ENCINAS CANTALAPIEDRA, Arturo Universidad Francisco de Vitoria

@arturo.encinas@ufv.es
Recibido / Received 10 de mayo de 2021

- Aceptado / Acepted 10 de junio de 2021

LIN, Alexandra

Universidad Francisco de Vitoria

@ si.alexandralin@gmail.com

\title{
Destrucción del mundo y sustitución en A.I. Artificial Intelligence, de Spielberg
}

World Destruction and Substitution in Spielberg's A.I. Artificial Intelligence

El artículo estudia la relación que A.I. Artificial Intelligence (Steven Spielberg, 2001) establece entre la destrucción del mundo y las dinámicas de sustitución. La proliferación de sustitutos robóticos es signo de una cultura puramente comercial y egoísta que cosifica a los otros y desencadena un proceso anticosmogónico (cosmolysis). Tanto la estructura dramática de la película como la realización, la iluminación o los símbolos (como el círculo), comunican este sentido trágico de un mundo posible fundado en la sustitución.

PALABRAS CLAVE: A.I. Artificial Intelligence, anticosmogonía, mundos posibles, Spielberg, sustitución.

The article studies the relationship that A.I. Artificial Intelligence (Steven Spielberg, 2001) establishes between the destruction of the world and the dynamics of substitution. The proliferation of robotic substitutes is a sign of a purely commercial and selfish culture that objectify others and leads to an anti-cosmogonic process (cosmolysis). The dramatic structure of the film, the filmmaking, the lighting and the symbols (such as the circle) all communicate this tragic sense of a possible world based on substitution.

KEY WORDS: A.I. Artificial Intelligence, anti-cosmogony, possible worlds, Spielberg, substitution.

\section{INTRODUCCIÓN ${ }^{[1]}$}

El artículo defiende la siguiente hipótesis: A.I. Artificial Intelligence (Steven Spielberg, 2001) muestra que la destrucción del mundo es consecuencia de una cultura de la sustitución. Dos evidencias animan a estudiar la validez de la hipótesis. En primer lugar, la narración de Spielberg avanza hacia el fin del mundo. El prólogo nos sitúa en un futuro en el que la acción del hombre ha provocado, por un lado, grandes inundaciones en ciudades importantes y, por otro lado, desigualdades sociales a escala global. La última parte de la historia sucede bastantes años después, en un planeta Tierra anegado por el hielo y donde la humanidad dejó de existir hace mucho tiempo. 
La segunda evidencia que motiva la hipótesis son las recurrentes dinámicas de sustitución a lo largo del metraje según el siguiente esquema: un robot sustituye a un ser humano en un rol concreto; los humanos en torno atribuyen al sustituto alguna culpa; comienza un proceso de eliminación del robot señalado como responsable de algún mal que sufre el grupo humano. Tanto la trama principal como las subtramas están motivadas por la sustitución, cuyos resultados, tarde o temprano, terminan siendo trágicos ${ }^{[2]}$.

La acción principal (marcada por la sustitución) no se presta a una relación de causalidad narrativa que explique el cambio de estado planetario entre el comienzo y el final de la historia. No obstante, sostendremos que en el ámbito temático esos mecanismos de sustitución sintetizan el modo de vida que efectivamente es causa de la destrucción del mundo. Como veremos, la cantidad de elementos cinematográficos que apuntan a esta relación es abrumadora. Para validar la hipótesis recurrimos a una metodología que integra varias perspectivas: la hermenéutica de los mundos posibles, la teoría mimética de René Girard y el análisis audiovisual.

«l'm sorry I dind't tell you about the world». Son las últimas palabras que Monica Swinton dirige a David antes de abandonarle en el bosque. A partir de ese momento la realidad que rodea al niño robot transita del calor hogareño a la hostilidad de una existencia cruel. Ese mundo al que se refiere Monica no es exclusivamente lo que se entiende por «universo material», sino que también indica la manera en que la persona habita la realidad. El mundo es un sistema de posibilidades. Eso es, en líneas generales, a lo que tanto Monica como nosotros nos referimos cuando decimos «mundo». La forma de habitar lo concreto siempre es humanamente experimentada en clave de mundo y no solo como universo físico o como medio biológico (Zubiri, 2010, pp. 166-201). Por ello, cuando el Dr. Know envía a David «at the end of the world where the lions weep", meta de su peregrinación, puede entenderse que el protagonista también se dirige hacia los límites, no solo del mero espacio físico, sino del espacio existencial, donde se encontrará con su creador, el profesor Hobby.

Esta idea de mundo, que desarrollan Zubiri, Guardini (2014, pp. 15-43, 70-82) o Marín (2019, pp. 461-465), entre otros, es la que encontramos en la propuesta teórica de los mundos posibles poéticos de García-Noblejas (2005, pp. 180, 206-207, 212). También existen planteamientos en parte parecidos en textos de Pavel (1986) y Eco (1994, pp. 64-82). Este punto de vista (que podríamos llamar fenomenológico-existencial) entiende los mundos de ficción desde una perspectiva antropológica y ética: lo que hay en juego en ellos no es ni la verificación extensional (García Noblejas, 2005, p. 180), ni de las proposiciones de la lógica (Pavel, 1986, p. 136; Eco, 1993, pp. 176-178). No se trata de la evaluación de distancia con respecto a nuestro universo material en sentido naturalista, sino de su oferta cautivante de posibilidades vitales de sentido y su contribución a la configuración de la identidad personal (García Noblejas, 2005, p. 17). Si admitimos que el telos narrativo de A.I. avanza hacia la destrucción del mundo (en su sentido más antropológico que cosmológico) como consecuencia de las acciones humanas (valoradas en su dimensión ética) parece adecuado adoptar la perspectiva de los mundos posibles, pues es sensible a este sentido de mundo que parece sugerir Spielberg.

Esclarecer la figura de mundo de A.I. hace imprescindible el estudio de los asuntos más importantes contenidos en el conflicto de la acción principal, y entre ellos destacan con una fuerza particular la sustitución y la chivoexpiación. La teoría de René Girard conoce bien estos asuntos (Girard, 1989; 2010; 2012). No nos limitaremos al análisis de la obra de Spielberg desde la teoría mimética, sino que procuraremos captar lo que la propia película aporta a la 
comprensión de los mecanismos de sustitución. La incorporación de la teoría mimética a la hermenéutica de los mundos posibles nos sitúa en la perspectiva adecuada para hacernos cargo de una de las grandes preguntas que trata la película: ¿es viable/posible un mundo dominado por dinámicas de sustitución?

Si lo que se quiere es analizar una película como tal, esto es, como relato audiovisual, y no solo como argumento, es imperativo prestar atención a los movimientos de cámara, la iluminación o el montaje, entre otros elementos que sugieren la posición discursiva de la obra ante el tema tratado en ella. La atención a la dimensión audiovisual de la cinta, además, ayuda a mostrar la unidad y coherencia internas entre elementos formales y el sentido general de la trama. Aunque no las referenciemos a cada momento, el texto se sirve de obras fundamentales, como la de Castillo (2016), en la que se da buena cuenta de los fundamentos de este lenguaje. Nuestra perspectiva de análisis audiovisual es cercana a la escuela iconológica (Brisset, 2011, pp. 94-99) con un marcado acento poético (García-Noblejas, 1988) ${ }^{[3]}$.

Establecido tanto lo que nos interesa de A.I. como el marco teórico desde el que operamos, queda indicar el camino que vamos a recorrer. En primer lugar, vamos a exponer las características de este mundo posible que avanza hacia su fin trágico, en lo que podría entenderse como una anticosmogonía. Veremos que la causa eficiente del destino de este mundo de ficción son los actos desordenados del hombre, cuyo origen está en una crisis tanto mimética como del deseo. En segundo lugar, hablaremos de ese proyecto vital destructivo, la sustitución, un modo de existencia a caballo entre el consumismo, la cosificación y las costumbres sacrificiales que encontramos en mitos y ritos antiguos. Veremos que el sustituto es una suerte de producto de mercado que suplanta al otro, pero que es expulsado y sacrificado cuando ese otro sustituido retorna o cuando es preciso encontrar un chivo expiatorio que calme el malestar de la comunidad. El mecanismo de sustitución se plantea como una mentira que mantiene encerrados a los implicados en ella y conduce a un fin trágico. En este sentido, el uso de los círculos en la película revela de forma elocuente la verdad de la sustitución en A.I. y sella su sentido general. Finalmente ofreceremos nuestras conclusiones con la esperanza de haber validado satisfactoriamente la hipótesis de la investigación: la primacía de una lógica vital sustitutoria, según la película de Spielberg, conduce a la aniquilación del mundo.

\section{LA DESTRUCCIÓN DEL MUNDO. INDICIOS DE UNA CAUSA MORAL ORIGINADA EN EL DESEO DESORDENADO}

\subsection{La cosmogonía de un relato anticosmogónico}

Notemos el contraste entre el estado del globo terráqueo al inicio y al término de A.I. La película comienza con un prólogo que plantea una narrativa solemne y de aroma mitológico. Un plano general del mar caótico y embravecido, lugar por excelencia del comienzo de la cosmogénesis en los relatos antiguos (Champeaux y Sterckx, 1985, p. 35), abre el filme. Una voz en off indica que los actos del hombre han provocado desórdenes planetarios tanto en lo medioambiental como en lo social. Las urbes más icónicas de la civilización son pasto del fluir indiferenciado de corrientes marinas. Entre este momento y el final de la película trascurren 2000 años, una elección argumental no exenta de referencias religiosas (Alba, 2017, pp. 172-173). 
En ese futuro, en la conclusión de la cinta, el planeta está congelado y la humanidad, causante de la desolación, no existe; el mundo en sentido estricto ha desaparecido ${ }^{[4]}$.

El recorrido de esta película, aunque formalmente comienza como una cosmogonía supone lo contrario. Resulta ser una historia del origen del mundo a la inversa, lo que podríamos llamar anticosmogonía ${ }^{[5]}$, cosmolysis ${ }^{[6]}$, cosmoekmedenise ${ }^{[7]} \mathrm{o}$, simplemente, un relato de la destrucción del mundo ${ }^{[8]}$. No es un mero deshacerse, o un retroceso de la naturaleza que se repliega sobre sí misma. Tampoco parece haber una intervención divina que lo cause. Son acciones humanas valoradas como moralmente negativas las que originan la anticosmogonía. El telón de fondo de A.I., por tanto, es el fin del mundo en este sentido de cosmolysis, y toda la película se dirige a él como punto de llegada.

La totalidad de la existencia (mundo) parece estar representada en el planeta Tierra (porción del universo material). A.l. se sitúa en un futuro muy desarrollado tecnológicamente, pero la conquista del espacio no se ha producido. La fábula está adherida a la superficie terrestre. Este hermetismo planetario infranqueable quizá sugiere que la Tierra funciona como imagen del espacio existencial, más allá del cual está la nada, el no mundo, la imposibilidad absoluta. Por estos motivos creemos más adecuado concebir nuestro planeta en la obra de Spielberg como un símbolo, lo cual nos aleja de un paradigma interpretativo exclusivamente ecológico (el hombre destruye el planeta por su falta de conciencia medioambiental) y nos sitúa en una perspectiva antropológica y ética (la bajeza moral aniquila las posibilidades de desarrollo de la persona y asola el único espacio existencial a su disposición).

\subsection{El origen de la caída moral: una crisis mimética}

En A.I. todos los personajes humanos con cierto peso narrativo se caracterizan por la bajeza moral de sus $\operatorname{actos}^{[0]}$. Las acciones humanas más nobles están silenciadas en la película. Esto ha llevado a Kendrick a defender que «the film suggests that jealousy, anger, and violence, rather than dreams and hopes, are the fundamental elements of human nature» (Kendrick, 2014, p. 182). No obstante, estos actos humanos son valorados negativamente (como una desviación, no como la esencia de lo humano) y esto es tanto como afirmar que el fin de la naturaleza humana, su telos, está frustrado en un relato temáticamente «antitélico». Este anti-telos antropológico tiene su correspondencia con el telos narrativo que conduce a la cosmoekmedenise.

Mientras que la primera parte del prólogo informa sobre la situación global del mundo de ficción, la segunda es un concilio de científicos. En la reunión el profesor Hobby plantea una crisis. Hasta el momento, los robots (mechas, mechanics) que han fabricado solo imitan los comportamientos externos de los humanos, pero no son capaces de amar de verdad, pues, a fin de cuentas, no son humanos. Los mechas todavía no imitan lo suficientemente bien. Hobby quiere responder a la insuficiencia imitativa generando mechas semejantes al humano (orgas, organics) lo que podría acelerar una crisis mimética que haga necesarias las sustituciones sacrificiales (sobre este tipo de aceleraciones véase Girard, 2012, p. 70). Pero esta crisis, tal y como es teorizada por Girard, no termina de suceder en la cinta. En este mundo de ficción los mechas no buscan sustituir a nadie, sino que las personas los quieren como sustitutos para luego convertirles en chivos expiatorios. Lo que hay en juego no es la rivalidad entre sujetos que surge de una mímesis de apropiación, tampoco la especulación canónica de la ciencia ficción sobre la rebelión de las máquinas contra sus creadores. El asunto es mucho 

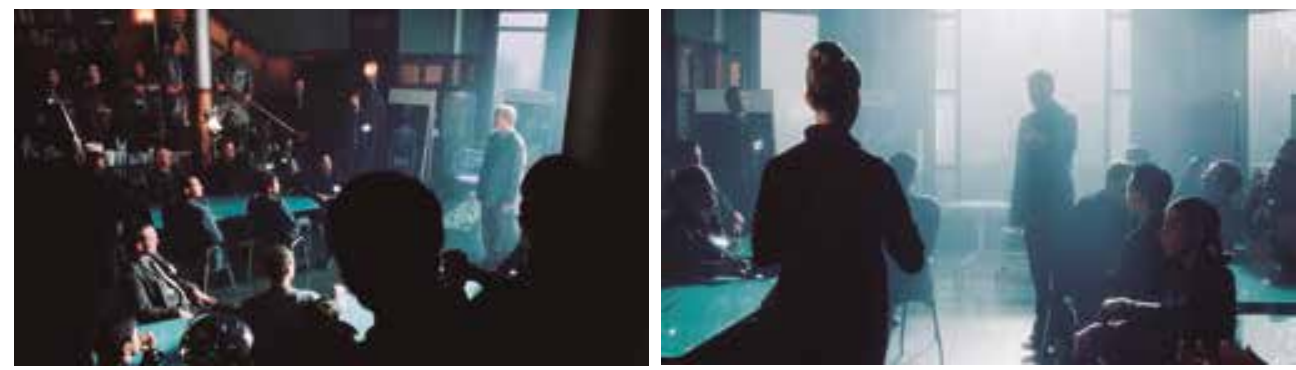

Figura 1. A.I. Artificial Intelligence, Steven Spielberg, Figura 2. A.I. Artificial Intelligence, Steven Spielberg, 2001. 2001.

más cruel y, en cierto sentido, tiene que ver con el deterioro del esquema de existencia del orga, y no tanto con el mecha como amenaza real.

Los empleados de Cybertronics se reúnen en una sala rectangular atravesada a lo largo por el eje de miradas que establece Hobby (figuras 1 y 2 ). Spielberg coloca al profesor delante de un poderoso contraluz, de modo que pareciera que los congregados son iluminados por él. La puesta en escena también habla de la centralidad del profesor. El eje de miradas inicial se mantiene hasta que a izquierda y a derecha sus colegas comienzan a interpelarle. Dichas réplicas hacen que el orden del eje establecido por Hobby esté en peligro. Por ello la cámara describe un movimiento combinado de travelling y panorámica buscando un nuevo eje. La cámara vuelve a describir otro travelling con panorámica que ahora sí funda el nuevo y definitivo eje que dominará durante el resto de la escena y que supone una ligera variación con respecto al eje primero (figura 3). La nueva posición de cámara, junto con el cambio de postura del profesor (ahora sentado) y la pérdida del formidable contraluz, coinciden con la novedad moral que la interlocutora de Hobby introduce en la discusión.

Su colega cuestiona a Hobby: «With all this animus existing against mechas today, it isn't simply a question of creating a robot who can love. But isn't the real conundrum, can you get a human to love them back? ». La respuesta de Hobby es elusiva: "Ours will be a perfect child caught in a freeze-frame, always loving, never ill, never changing». Y añade: «With all the childless couples yearning in vain for a license, our little mecha will not only open up a completely new market, but it will fill a great human need». La mujer le recrimina: «But you haven't answered my question», e insiste: «If a robot could genuinely love a person, what responsibility does that person hold toward that mecha in return? ». Los mechas de este mundo posible solo se dedican

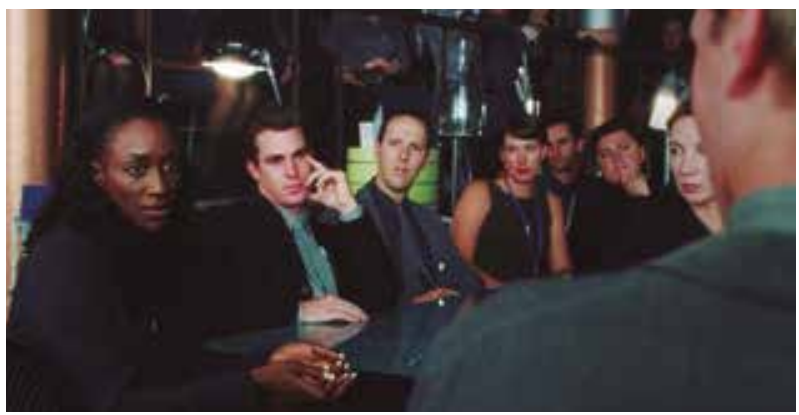

Figura 3. A.I. Artificial Intelligence, Steven Spielberg, 2001. 


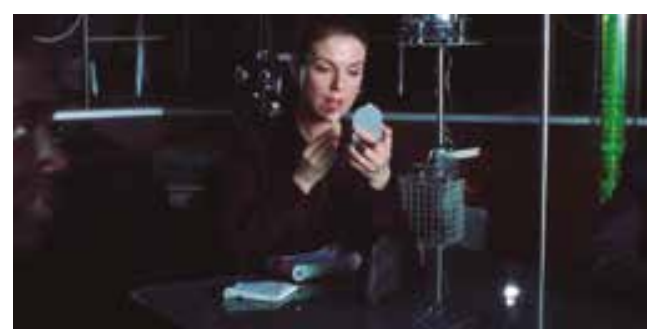

Figura 4. A.I. Artificial Intelligence, Steven Spielberg, 2001.

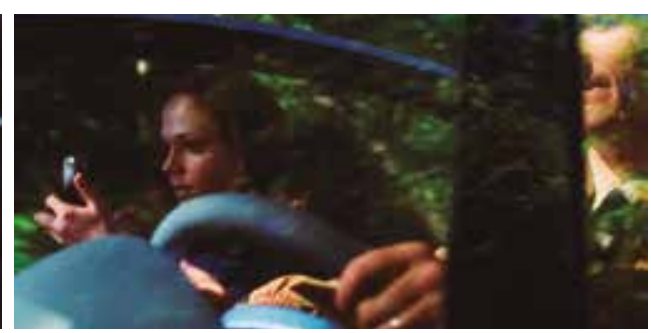

Figura 5. A.I. Artificial Intelligence, Steven Spielberg, 2001.

a dos cosas, o bien dan placer o bien trabajan (Morrissey, 2004, p. 254) y la interlocutora del profesor seguramente intuya que ese robot que ama termine engrosando una de estas dos categorías. Por ello concluye su intervención haciendo explícito lo que ya estaba del todo claro: «It's a moral question, isn't it?». Hobby no responde directamente, pero aporta las claves interpretativas para valorar el resto del metraje: «The oldest one of all. But in the beginning, didn't God create Adam to love Him?». La última réplica del profesor consigue dos cosas: acalla la voz de esta mujer, posible imagen de la conciencia, y la diluye en el murmullo de unos asistentes poco interesados en la cuestión moral; y «reaffirms his God complex and uses it to justify his hubris in creating David» (Kendrick, 2014, p. 185), a la vez que pretende borrar las responsabilidades morales derivadas de ese acto «creador» (p. 89).

En medio del desordenado cruce de pareceres (un rumor caótico, como el del mar en la escena previa), Spielberg acerca la cámara con un travelling in a un robot para ofrecernos un plano medio (figura 4). El robot no es capaz de comprender el dilema moral que plantea la colega de Hobby. Ante el desconcierto, dicho autómata activa uno de los programas previstos; en este caso, pintarse los labios. El director tiene mucho cuidado en cerrar la escena con esta imagen y abrir la siguiente con otro plano medio de una mujer que también se pinta los labios (figura 5), Monica. El montaje asociativo vincula al robot y a la madre: el mecha, incapaz de entender el dilema moral, se entrega a labores cosméticas; Monica eludirá la voz de su conciencia y terminará por abandonar a David en el bosque, alejándose del lugar montada en el mismo coche que le vio aparecer en la narración.

\subsection{La atrofia del deseo: el amante perfecto y eterno como sustituto del otro}

Volvamos por un momento a la respuesta de Hobby a su colega con inquietudes morales. Las palabras del profesor tienen un aroma cosmogónico, pues remiten al relato de la creación veterotestamentaria (Gn 1-2). El escenario de A.I. recuerda otros pasajes próximos al de la creación que evocan desastres mundiales cuyo origen es la maldad humana. Las proximidades en las que se celebra la reunión de los científicos (lo sabremos más tarde) están inundadas, igual que el orbe en el episodio del diluvio (Gn 6,5-7,24). La sala se sitúa en la zona elevada de un rascacielos que, en este contexto, bien pudiera guardar semejanza con Babel (Gn 11,1-9).

Los mitos antiguos muestran a unos dioses o héroes arcaicos que llevan a cabo unas acciones ejemplares in illio tempore que fundan el mundo. Cuando el homo religiosus quiere hacer habitable un espacio, esto es, volver a fundar el mundo, debe imitar ritualmente la acción 
arquetípica ab origine del dios creador o héroe mitológico (Eliade, 2012, pp. 29-31, 42-44). En la película de Spielberg, por el contrario, la humanidad se imita a sí misma en su error. Por ello, lo que consiguen es lo contrario a la extensión del mundo habitable y propician el avance acelerado de la cosmoekmedenise.

La comprensión del texto genesíaco de la creación que manifiesta Hobby es algo diferente a lo que realmente aparece en el comienzo de la Biblia. En el libro del Génesis Dios crea al hombre a su imagen y semejanza. La creación bíblica es un acto de amor gratuito y libre. Dios no crea por una necesidad natural. La creación no viene a llenar una ausencia en Dios (Guardini, 2014, pp. 28-30). El profesor no lo entiende así y dice: «Didn’t God create Adam to love Him?». Hobby «creates multiple robotic simulacra» de David, su hijo muerto, y Monica «'adopts' a robotic simulacrum of David to fulfil her desire to continue be a mother in the event of losing her own son", Martin; «In both cases, the grief of losing a child propels a parent towards substituting, or replacing, their lost human 'original' with a mecha 'sequel'» (Jess-Cooke, 2006, p. 349). Este niño robot parece que viene a suplir una ausencia, una necesidad materna, un deseo orientado perversamente (Williams, 2017, p. 253). El egoísmo de la acción se ve reforzado por el hecho de que: «During the imprinting process, she neglects to include Henry as an object of David's love, thus keeping his singular devotion for herself» (Dunn, 2008, p. 85). «Thus, David is, through no fault of his own, the ultimate expression of human selfishness» (Kendrick, 2014, p. 189). La película concibe el deseo de forma circular y repetitiva, como lo siempre insatisfecho (Jess-Cooke, 2006, p. 349).

Según el relato del Génesis, Dios creó al hombre libre, tanto para amarle como para lo contrario. Hobby pretende crear un robot que ame. Olvida, no obstante, que esa facultad implica la libertad de elegir el amor en lugar de su negación. La creación del científico, en realidad, no es capaz de amar. Eso que Hobby llama «amor» no es elección libre, sino una imposición, la única opción, o, como se denomina en la película, «la impronta».

Aunque exteriormente los actos de David puedan parecer de amor verdadero, hasta el punto de que algunos han afirmado que no se puede determinar con seguridad que no sean tales (North, 2017, p. 402) o, incluso, que son signo de que David es «singular and unique» (Kendrick, 2014, p. 171), en realidad, no se corresponden con la auténtica dinámica del amor. De hecho, el relato lleva hasta el extremo la separación entre el mecha y Monica para dejar claro que David no puede elegir no buscar hasta el final a la que le repudió para siempre. He aquí otro aspecto del gran yerro de la humanidad según la película: fabricar lo no fabricable, pretender lo imposible, intentar que una solución tecnológica resuelva lo irresoluble. Los protagonistas humanos de A.I. pretenden evitar los aspectos trágicos de la naturaleza humana (la pérdida de alguien cercano, o satisfacer el deseo de amor) por medio de la ciencia y la técnica (Dunn, 2008, p. 88). Estos son los actos que tornan el espacio inhabitable, que, queriendo salvar la existencia, solo aceleran la anticosmogonía. Lo que activa todo este proceso es un cierto tipo de sustitución.

\section{LA SUSTITUCiÓN, UNA CULTURA de LA MUERTE}

\subsection{El producto que sustituye al otro}

Centrémonos en otros dos datos que aporta el prólogo: «a high degree of prosperity survived when most governments in the developed world introduced legal sanctions to strictly 


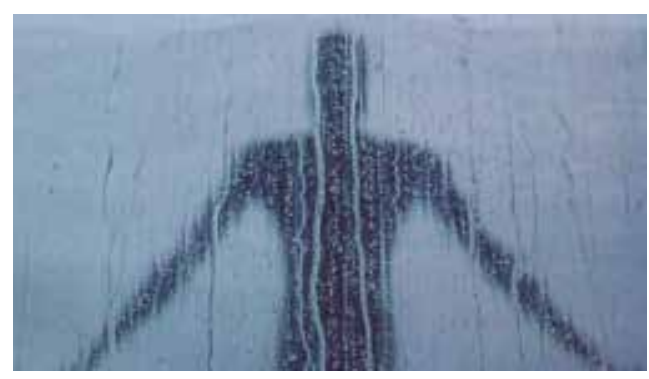

Figura 6. A.I. Artificial Intelligence, Steven Spielberg, 2001.

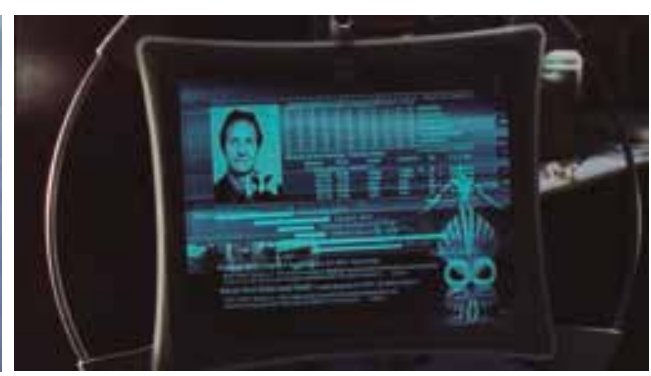

Figura 7. A.I. Artificial Intelligence, Steven Spielberg, 2001.

license pregnancies», lo que apunta a una crisis de generatividad; "which was why robots, who are never hungry and who did not consume resources beyond those of their first manufacture, were so essential an economic link in the chain mail of society ". La reunión de científicos podría entenderse mejor como un evento de empresa en el que se estudia el lanzamiento de un producto nuevo: David (Williams, 2017, p. 253). Por ello a la sagaz colega del profesor le resulta tan extraña la lógica comercial que envuelve la creación del niño robot que ama, aunque ya sabemos que no ama.

En cualquier caso, los fabricantes de sustitutos plantean todo el asunto desde una perspectiva empresarial: detectan un nicho de mercado y tienen la tecnología para responder a esa demanda. Esa pregunta moral, «The oldest one of all», no integra el plan de negocio. Pues bien, como todo proyecto empresarial con cierto alcance, Cybertronics es reconocible por su logotipo. Es la segunda imagen de la película, que aparece tras un encadenado, como traspasando las aguas primordiales. Es una figura humanoide minimalista que procede de una concha marina (figura 6). Las habituales apariciones de la imagen de Cybertronics a lo largo del metraje hacen pensar en su importancia (figuras 6 a 16). Parece que este ser antropomórfico reúne los atributos impersonales del perfecto sustituto que, al igual que el mecha, provoca nuestro extrañamiento: parecía como nosotros, pero en realidad no es de los nuestros.

Aunque Hobby sostiene que el producto estrella de Cybertronics es un niño y que ama de manera auténtica, tantas veces el logo de la compañía parece sugerir que David es una de las muchas ofertas del catálogo de una empresa tecnológica (figuras 9, 10, 12, 13, 14). Aquí destaca especialmente el plano general en el que el mecha camina entre las cajas que contienen a otros como él (figura 17). El científico cree que puede reducir el amor a la lógica económica
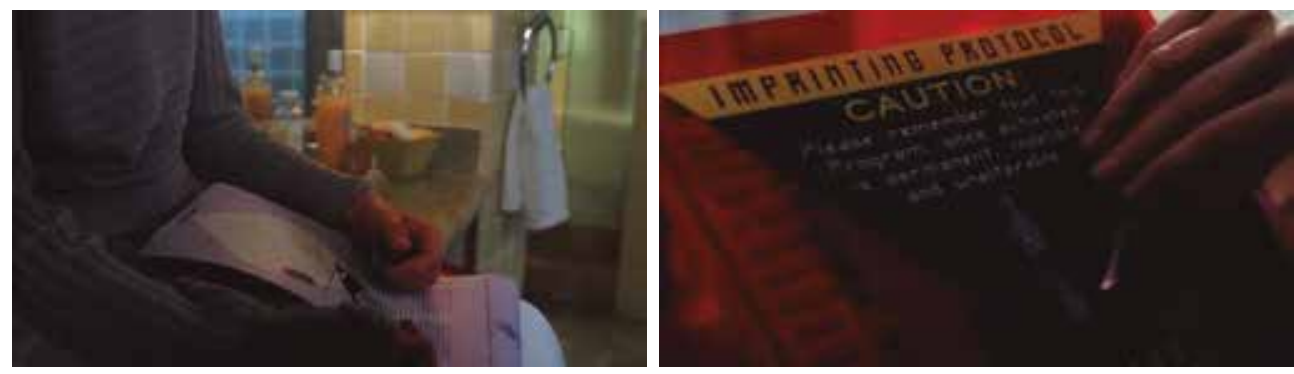

Figura 8. A.I. Artificial Intelligence, Steven Spielberg, Figura 9. A.I. Artificial Intelligence, Steven Spielberg, 2001. 2001. 

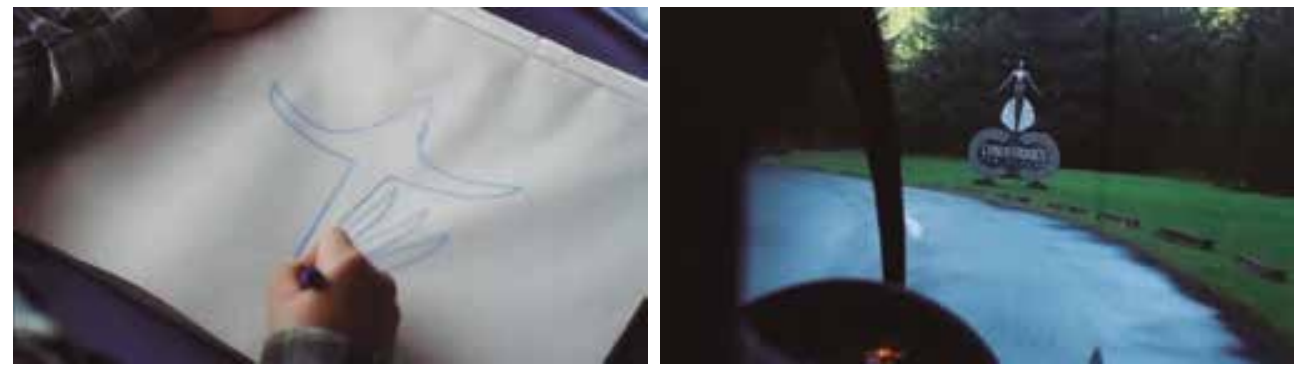

Figura 10. A.I. Artificial Intelligence, Steven Spielberg, Figura 11. A.I.Artificial Intelligence, Steven Spielberg, 2001. 2001.
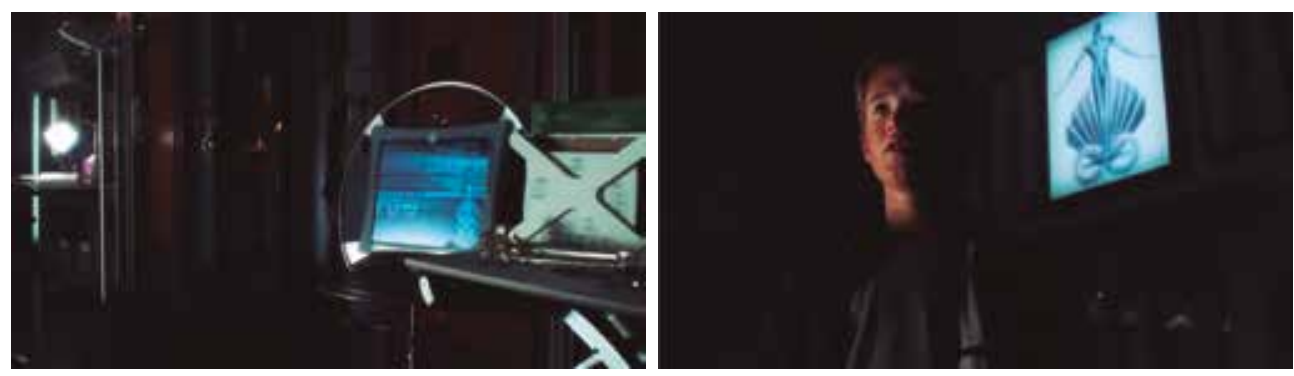

Figura 12. A.I.Artificial Intelligence, Steven Spielberg, Figura 13. A.I.Artificial Intelligence, Steven Spielberg, 2001. 2001.
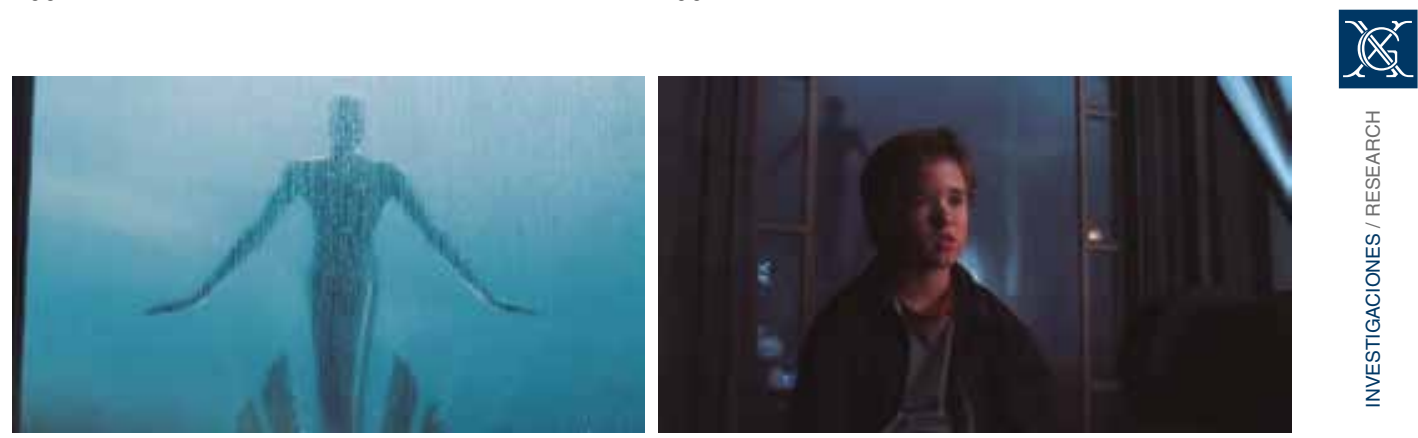

Figura 14. A.I. Artificial Intelligence, Steven Spielberg, Figura 15. A.I. Artificial Intelligence, Steven Spielberg, 2001. 2001.
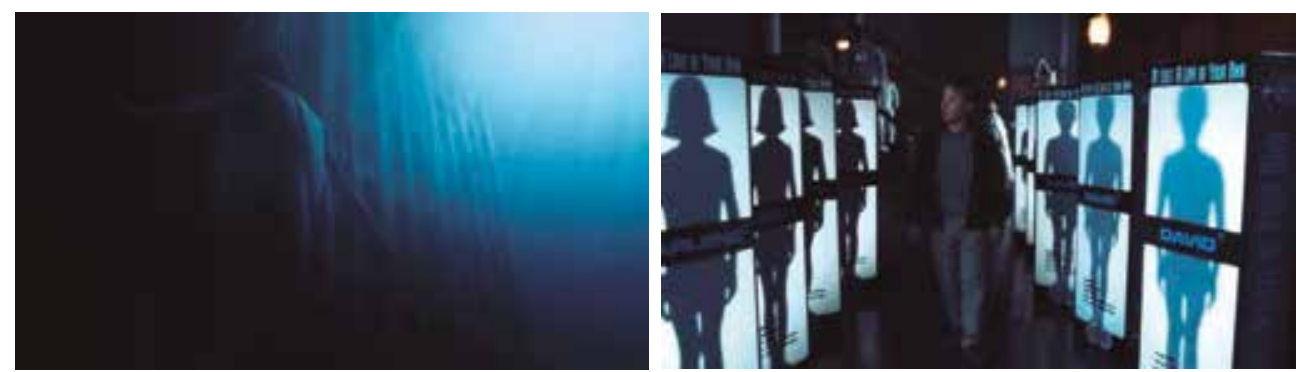

Figura 16. A.I. Artificial Intelligence, Steven Spielberg, Figura 17. A.I.Artificial Intelligence, Steven Spielberg, 2001. 2001. 

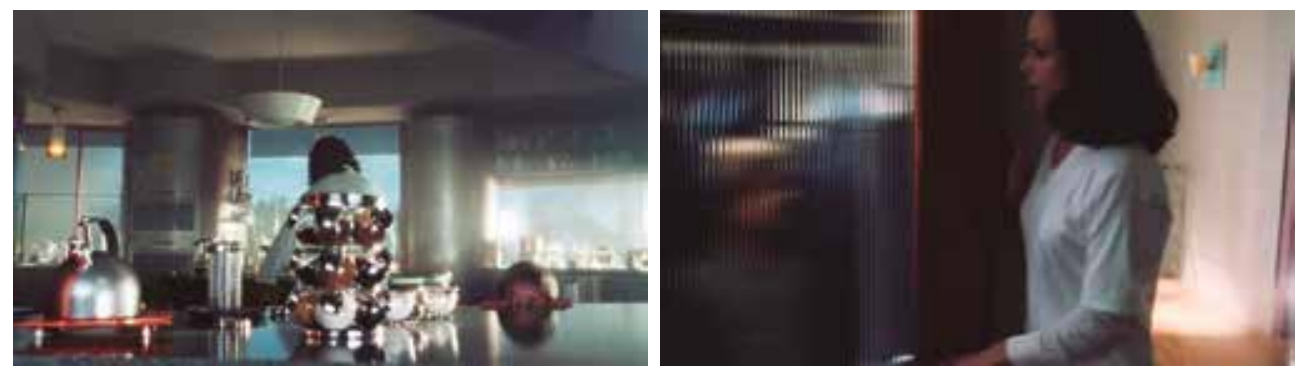

Figura 18. A.I. Artificial Intelligence, Steven Spielberg, Figura 19. A.I.Artificial Intelligence, Steven Spielberg, 2001. 2001.
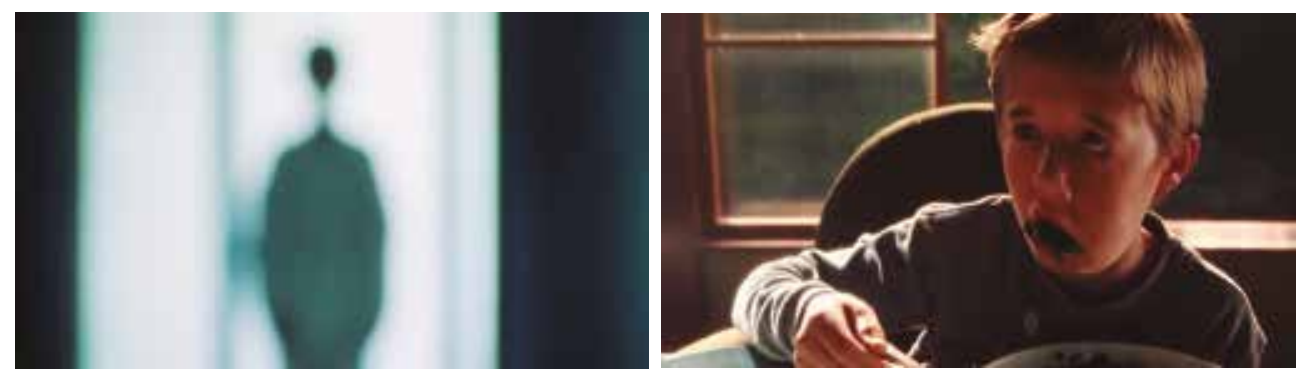

Figura 20. A.I. Artificial Intelligence, Steven Spielberg, Figura 21. A.I. Artificial Intelligence, Steven Spielberg, 2001. 2001.

del mercado, a mero producto, seguramente porque su idea del amor es esa; y he aquí otra dimensión del mal moral que destruye el mundo según $A . I$.

Hay más pruebas que refuerzan la idea de que David es un mero producto: el plano en el que tanto el mecha como la cafetera se reflejan en la encimera de la cocina, sugiriendo la misma condición maquinal (figura 18), un efecto muy parecido al del logo de Cybertronics (figura 7); David tras el cristal esmerilado, que evoca la naturaleza no humana del robot y la extrañeza de Monica (figura 19), aunque estas deformaciones pudieran remitir a la imagen distorsionada de la humanidad, transversal a toda la película (Alba, 2017, p. 177); el plano desenfocado de la primera aparición de David (figura 20), donde su silueta es semejante a la de otros robots, los especialistas (mechas de última generación, los más avanzados tecnológicamente); el rostro de David descomponiéndose tras comer verduras (figura 21); el hecho de que, a diferencia de Pinocho, no crezca, ni aprenda ni madure (Morrissey, 2004, pp. 252-254).

Los David y las Marlene (figura 17) son recursos que surgen de una ausencia, no de la gratuidad (de nuevo la referencia genesíaca). Todos los robots son sustitutos y sustituibles, por ello no acaban de sustituir y se les puede destruir, y por ello son replicables también. «He's so real, but he's not», «Monica says when she first sees him, essentially summarizing David's identity crisis» (Kendrick, 2014, p. 176). David experimentará la crisis mimética de la indiferenciación cuando, al llegar «at the end of the world where the lions weep», la sede de Cybertronics, encuentre a otro como él, un doble recibido como una amenaza a su pretendido ser singular e insustituible (Dunn, 2008, p. 86; Zamorano, 2009, p. 152). Este gemelismo resulta insoportable para él y, como ocurre en los mitos, toma el camino ancestral de la eliminación del otro: "You can't have her», dice al otro simulacro de David, que nada sabe de Monica. Martin también consiguió resolver la crisis de indiferenciación con David previamente, pero su método es 


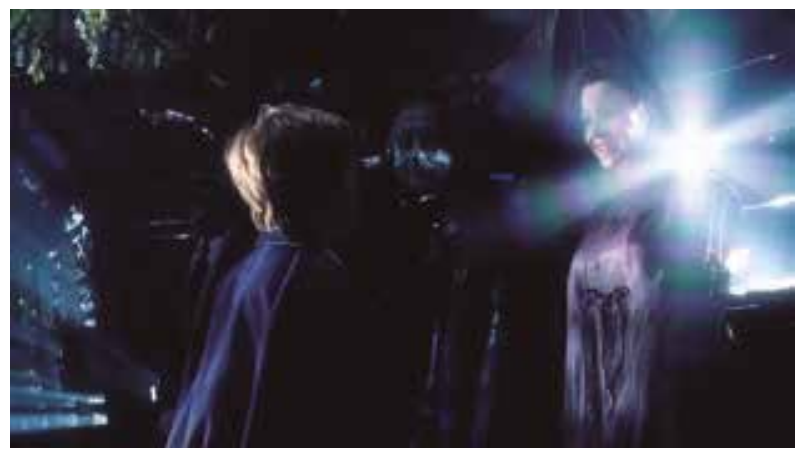

Figura 22. A.I. Artificial Intelligence, Steven Spielberg, 2001.

más refinado que la reacción primitiva del robot. Spielberg todavía da un paso más. Instantes después, al conocer la lógica comercial de la que forma parte, el mecha comprende que nunca será un niño de verdad, por lo que Monica no le aceptará. Como no podrá cumplir su fin último, "amar» incondicionalmente a Monica, se lanza a ese mismo mar del que parece emerger el logo de la compañía (figura 15). En este sentido, David no es muy diferente de la Smart TV que se desconecta cuando detecta inactividad por parte del usuario.

Se ha hecho notar que los robots del filme parecen más humanos que los propios humanos (Alba, 2017, p. 174; Williams, 2017, p. 255). ¿Lo son? Los robots cumplen sus funciones, no tienen otra opción. La niñera robot que auxilia a David en medio del ataque de los organizadores de Flesh Fair no acude en ayuda del resto de androides (figura 22). ¿Por qué? Porque es una niñera robot, ese es su programa y David parece un niño. No está siendo bondadosa, tampoco lo contrario. Los mechas fueron fabricados para realizar algo que humanamente se entiende como un bien (en este caso cuidar de un niño) y que los hombres han confiado en ellos. He aquí otra dimensión de la tragedia antropológica que porta la película: las personas han dejado en manos de sustitutos robóticos lo dignamente humano.

\subsection{La activación del producto-sustituto: el rito de la impronta}

Para el profesor el amor se activa por medio de un protocolo: el rito de la impronta, unas palabras que deben pronunciarse al mismo tiempo que se acciona un mecanismo del niño robot. Hobby tiene la pretensión de que este ritual funde el mundo, esto es, la llamada del mecha a la existencia humana. Todo es mero efectismo emocional para satisfacer al comprador. El quicio del mal en A.I., al igual que en su referencia literaria, Pinocho, es el egoísmo: «The single-minded quest of self-satisfaction at the expense of others -especially children» (Morrissey, 2004, p. 250).

La alocución en la que el profesor explica a sus colegas su propuesta del robot que ama (figura 2) y el rito de la impronta oficiado por Monica (figura 23) están retratados con un poderoso contraluz. Tanto por la iluminación, como por la puesta en escena (el mecha a la izquierda del encuadre, el humano a la derecha), como por la temática, ambos momentos están asociados. Además, Hobby y Monica, en algún punto de sus respectivas escenas, se arrodillan frente al mecha sentado, con todas las connotaciones religiosas que ello tiene. En su comentario a 


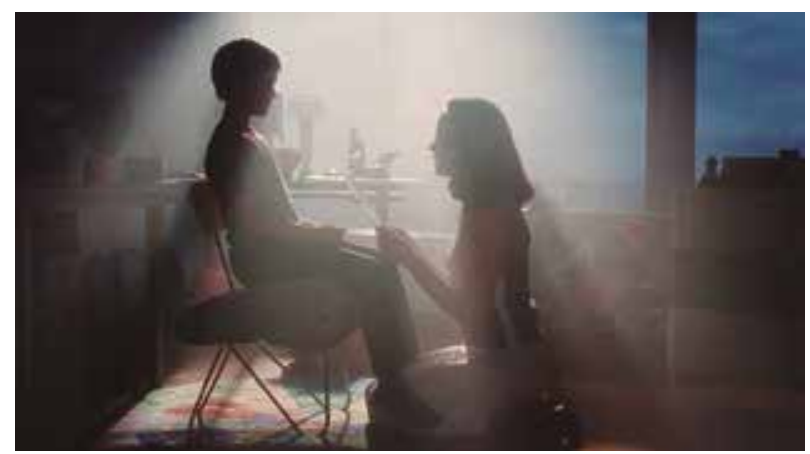

Figura 23. A.I. Artificial Intelligence, Steven Spielberg, 2001.

Ap 17-18, Poythress (2000) hace notar que la Bestia maligna instiga a la persona para que adore lo que teme (pp. 21-22). ¿No ocurre en la película de Spielberg algo semejante? La genuflexión frente al mecha y la promesa de Hobby, «will be a perfect child caught in a freeze-frame, always loving, never ill, never changing», ¿no es expresión de que lo que estos personajes temen es la soledad ocasionada por la pérdida del otro? Pero ¿no sucede también que esa robótica que quiere calmar el miedo a la contingencia (que se manifiesta eminentemente en la muerte y el dolor) provoca otros miedos, como el que acosa a Martin, es decir, el miedo a ser sustituido por el mecha?

Kendrick (2014) destaca el parecido de la puesta en escena del rito de la impronta con un tercer momento, el exilio. Monica también se arrodilla frente a David y también hay un contraluz poderoso y natural. Al respecto, Kendrick trae a colación la sentencia que David escribió en una ocasión: «DEAR MOMMY, I LOVE YOU AND HENRY AND THE SUN IS SHINING» (pp. 198-199).

Todavía hay una cuarta escena conectada con estas dos: la conversación de David con el Hada Azul (figura 24). David pide lo que Hobby promete y lo que Monica cree haber activado: un cambio ontológico que le transforme en un niño de verdad. Este ser fantástico, mera ficción creada por los especialistas dos milenios después del hundimiento de David, descorre el velo de la realidad: Spielberg cambia la planificación colocando al mecha en el lado derecho del encuadre; ahora el interlocutor del robot se sitúa por encima de David, no de rodillas; además, el contraluz ya no es natural, sino otra simulación, en este caso del Sol. La mentira ha sido definitivamente refutada.

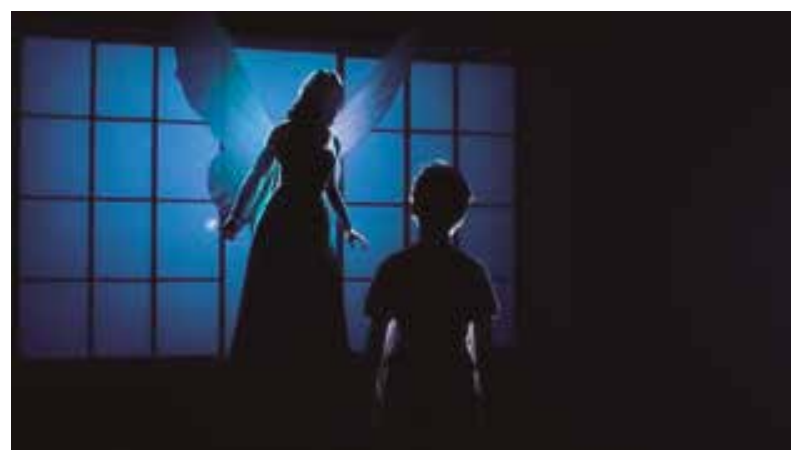

Figura 24. A.I. Artificial Intelligence, Steven Spielberg, 2001. 


\subsection{El efecto colateral y objetual de la sustitución}

David, el niño robot, es un producto de consumo y, como tal, puede ser tan oportuno en un momento dado como prescindible o reemplazable en una situación distinta. El mecha reemplaza al hijo en coma, Martin, lo que implica que ese hijo puede ser sustituido y, por lo tanto, el amado entra también en esta lógica del intercambio mercantilista. Tanto la individualidad de Martin como la de David retroceden para otorgar la primacía al deseo del que experimenta la pérdida, Monica.

En esta lógica de la sustitución el otro deja de tener valor por sí mismo y comienza a ser estimado exclusivamente con relación a los afectos propios. La relación deja de ser entre un «Yo» y un «Tú», para convertirse en la relación entre un sujeto y un objeto. Cuando no se ve en el otro un «Tú», no se le toma como ser en sí mismo, como ser que es el centro en cuyo torno se ordena todo en la forma única de mundo; sino que lo refiero a mí mismo y lo instrumentalizo para mis fines. No considerar al otro como «Tú, implica que el sujeto no adopta la actitud de "Yo», sino solo la de sujeto cognoscente activo. Frente al objeto el hombre está interesado solo objetivamente, su persona no muestra su rostro interior. Del encuentro sujetoobjeto surge provecho o perjuicio, pero no destino personal, porque la persona está acorazada (Guardini, 2014, pp. 130-133). Cuando el otro no es un «Tú» sino un objeto (y, como tal, sustituible) se puede comerciar con él. La evaporación de estas relaciones auténticamente personales es simultánea a la disolución del mundo.

En parte, esto es vislumbrado por Monica cuando espontáneamente declara: «There is no substitute for your own child!». En efecto, no lo hay; y pretenderlo lo envilece todo. La negación de esta intuición tan humana y sincera hace de Monica la madre más monstruosa del cine de Spielberg (Williams, 2017, p. 253).

\subsection{Vuelta del sustituido y expulsión del sustituto: chivoexpiación y sacrificio}

Williams ve con agudeza que Monica se refiere a Martin como «my son», pero nunca emplea ese término para David (2017, p. 254). Cuando Martin despierta del coma y vuelve al hogar comienza el proceso de expulsión del sustituto David. Un nuevo hijo de verdad hubiera agrandado el espacio existencial de la familia. Un retoño por encargo no ensancha el mundo, solo rellena, y cuando vuelve el legítimo heredero suscita una crisis mimética, la indiferenciación del gemelismo, que se salda con la liquidación del sustituto. Se realiza aquí la habitual progresión de la crisis mimética seguida por el fenómeno del chivo expiatorio (Girard, 2012, pp. 70-79). Precisamente porque es sustituto puede ser recibido con todos los honores a su llegada y, más tarde, depositado como un cachivache obsoleto en el bosque. El matrimonio es dueño del mecha, pues ellos lo compraron y pueden despedirlo cuando consideren; no en vano Monica arroja a David en el bosque y le da dinero (como un finiquito simbólico).

Antes de consumar el destierro tiene que suceder el proceso de identificación del robot como origen de los males que asolan a la comunidad. El primer interesado en resolver la crisis mimética por medio de este proceso de estereotipado sacrificial es Martin, que opera como un auténtico relator mítico. Diseña una escalada desde lo meramente molesto hasta situacio- 
nes de riesgo mortal que escapan a su control. Todo comienza con pequeños problemas, cada vez más peligrosos, hasta el incidente en la piscina: David y Martin son víctimas, pero el segundo casi muere ahogado. Los padres se lanzan al agua para rescatar a Martin, dejando olvidado en el fondo a David en una imagen que prefigura su destino fatal durante 2000 años de espera bajo el mar frente a una estatua del Hada Azul.

La fuerza de los hechos convence al matrimonio de que el único modo de purificar el hogar es devolver a David a Cybertronics para que lo desguacen, una opción que estuvo presente desde que adquirieron este producto. El chivo expiatorio puede ser sacrificado en aras del bien de la familia porque no es su hijo de verdad. David es imagen de la víctima arcaica por antonomasia, pues también él acepta los crímenes que le imputan (Girard, 1989, pp. 135-142); aunque sabemos que tanto David como Edipo son inocentes, no así el grupo (Girard, 2010, pp. 47-48). Incluso hace propósito de enmienda y asume una tarea ontológica que, de no ser imposible, resultaría digna de Hércules: conseguir ser un niño de verdad con la esperanza de volver al seno familiar.

Monica se encargará de conducir a esta víctima inocente al altar del sacrificio: Cybertronics. Tiene todo el sentido que los fabricantes de chivos sustitutos asuman el papel de ejecutores últimos del sacrificio. Como en Edipo Rey, Blancanieves o El Rey León, el encargado de liquidar al infante no culmina el crimen y simplemente lo sitúa lejos, casi en el límite de su mundo familiar, que a efectos prácticos pudiera ser tanto como darlo por muerto.

David está a punto de descubrir la cara más oscura de este mundo posible sacrificial, para lo que solo cuenta con unos dólares que le acaba de proporcionar Monica y la compañía del osito Teddy. La idea de que David es el juguete de Monica (Morrissey, 2004, p. 257) adquiere más fuerza al considerar que el peluche comparte su mismo destino. Teddy está al lado del mecha desde el comienzo. Se ha indicado que, por sus intervenciones, en las que suele disuadir a David para no transgredir las prohibiciones y para que se conduzca prudentemente por la vida, Teddy funciona como imagen de la conciencia de modo análogo al personaje de Pepito Grillo en el cuento de Pinocho (González y Morales, 2017, p. 177).

\subsection{Flesh Fair y Rouge City: recintos sacrificiales y unanimidad indiferenciada}

El bosque es el lugar en el que el protagonista se queda solo por primera vez, sin humanos alrededor (figura 25). Allí se encuentra con otros mechas que, al igual que él, han sido rechazados por la sociedad. Los robots del bosque se convierten en presas que van a ser cazadas por los humanos que las despedazarán posteriormente en Flesh Fair (figura 26). Masas enfurecidas acuden al evento para contemplar un auténtico sacrificio de robots que previamente fueron empleados para fines sustitutorios y que ahora resultan las víctimas perfectas. Gigolo Joe tiene claro el motivo de estas dinámicas: «They hate us [...] They made us too smart, too quick, and too many [...] when the end comes, all that will be left is us. That's why they hate us».

Se ha indicado (Alba, 2017, p. 182) que los planos del público en Flesh Fair se resisten a ofrecer rostros perfectamente nítidos (figura 27). Gracias a ello, Spielberg consigue plasmar una masa indiferenciada y unánime integrada por personas sin identidad. Los congregados en Flesh 

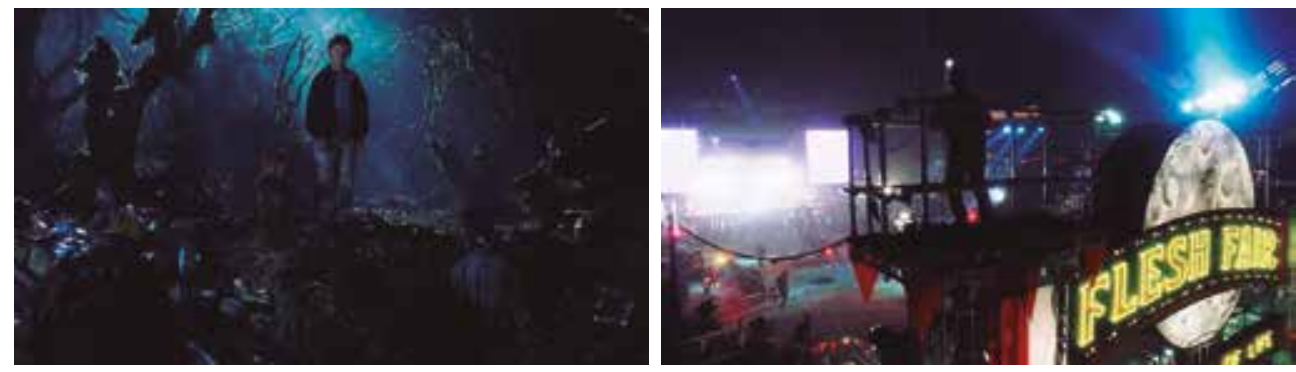

Figura 25. A.I. Artificial Intelligence, Steven Spielberg, 2001.

Figura 26. A.I. Artificial Intelligence, Steven Spielberg
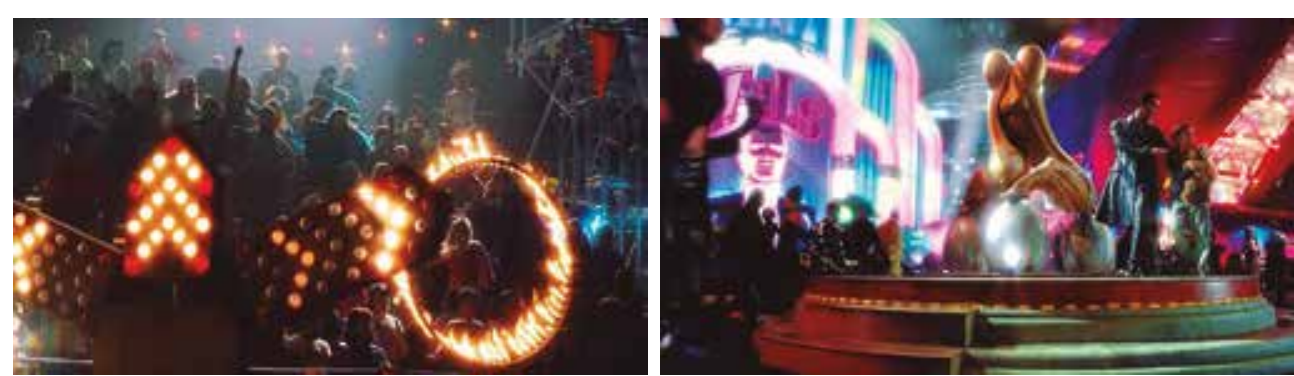

Figura 27. A.I. Artificial Intelligence, Steven Spielberg, Figura 28. A.I. Artificial Intelligence, Steven Spielberg, 2001. 2001.

Fair odian a los mechas, les culpan de sus desgracias y dirigen su furia hacia ellos. La humanidad se revela en masa contra los sustitutos que ellos mismos han fabricado. La confusión en este templo de la destrucción es tal que «blurs the line between orga and mecha, as they ultimately reject the destruction of David because he acts too human» (Kendrick, 2014, p. 186).

Rouge City muestra una sociedad comercial orientada a la diversión y satisfacción inmediata de los deseos del concupiscible. Los colores y las luces construyen la imagen de una gran sala de máquinas recreativas (figura 28). Solo la capilla dedicada a la Virgen María y las salas del Dr. Know parecen introducir ámbitos de reflexión y cultivo del espíritu. Tanto Flesh Fair como Rouge City son el reverso tenebroso del proyecto de mundo consumista-sustitutorio.

\subsection{La sustitución como ficción falsa}

David representa la crisis de la distinción entre los niveles de realidad, que se concreta en su incapacidad para relacionar adecuadamente la cotidianeidad con el tipo de verdad de los mundos de ficción, concretamente Pinocho (figura 29). "Martin makes the parallels between David and Pinocchio obvious to David in order to undermine his 'eligibility' for Monica's love" (Jess-Cooke, 2006, p. 355). La imagen de David atrapado durante 2000 años bajo el mar, dentro de la zona dedicada a Pinocho en un parque temático en Coney Island (figura 30), frente a la estatua del Hada Azul, pidiéndole que le convierta en un niño de verdad (figura 31), expresa cómo el mecha está atrapado en una fantasía mal entendida o, como diría North (2017), «he, lacking the semiotic skills to distinguish signs from their referents, takes for reality» (p. 402). Por su parte, la sustitución resulta un tipo de ficción perversa o, simplemente, una mentira con 

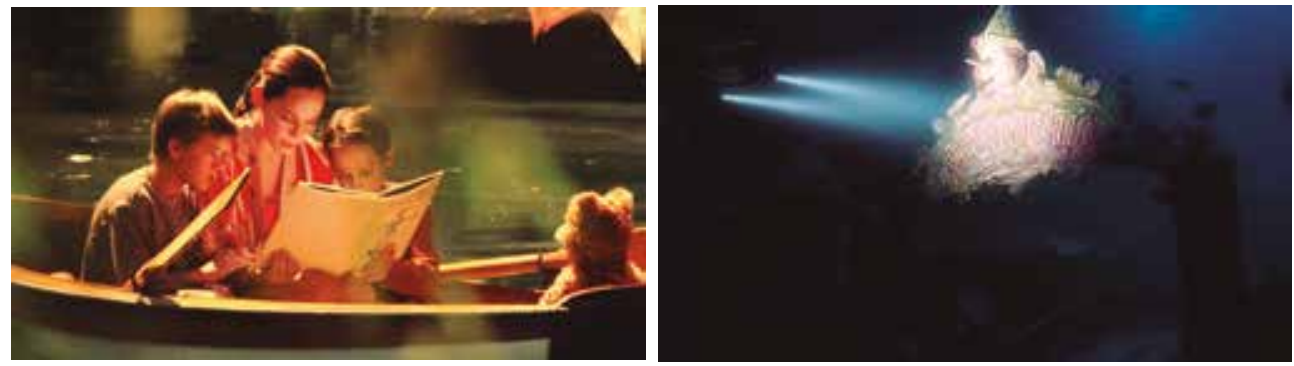

Figura 29. A.I. Artificial Intelligence, Steven Spielberg, Figura 30. A.I.Artificial Intelligence, Steven Spielberg, 2001. 2001.

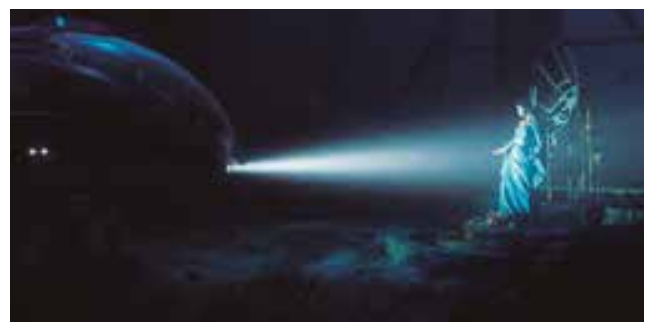

Figura 31. A.I. Artificial Intelligence, Steven Spielberg, 2001.

argumento: no es verdad que Gigolo Joe sea un amante, tampoco es cierto que David sea un hijo. La sustitución es una ficción falsa que conduce a la cosmoekmedenise. En este sentido, la escena en la sala de Dr. Know es especialmente significativa.

La escena de Dr. Know transcurre en una especie de teatro, lugar de representaciones ficcionales: butacas, telón, pantalla, proyecciones, hologramas, etc. (figuras 32 y 33). Gigolo Joe anima a David a preguntar al Dr. Kown dónde encontrar el Hada Azul que le transforme en infante humano real. Los mecha tendrán que combinar algunas de las diversas áreas de conocimiento que ofrece Dr. Know para obtener la respuesta que buscan. Bajo los signos del travelling que cruza el eje y el cambio de iluminación, lo que indica la introducción de una novedad epistemológica, descubren que deben relacionar las categorías flat facts y fairy tale en lugar de preguntar desde una sola de estas perspectivas. Esto sorprende enormemente a David: «But if a fairy tale is real, then wouldn't it be a fact?». Sabe que los fairy tales son verdad, pero lo son en un sentido que no se corresponde plenamente con el de los flat facts.
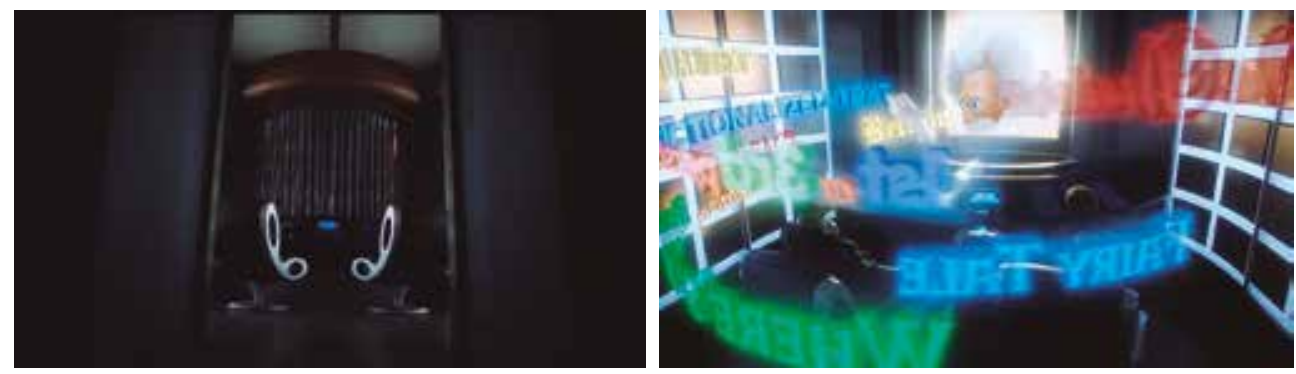

Figura 32. A.I. Artificial Intelligence, Steven Spielberg, Figura 33. A.I. Artificial Intelligence, Steven Spielberg, 2001. 2001. 
David y Gigolo Joe llegarán al lugar al que les envía Dr. Know, «at the end of the world where the lions weep", en la inundada Nueva York. Allí Hobby intenta sacar a David de su fantasía. Al descubrir que nunca podrá convertirse en un niño de verdad el mecha se lanza al mar para poner fin a todo, pero en un giro de la fortuna termina dentro de un vehículo en el que durante dos milenios permanece atrapado bajo una noria enfrente de la estatua del Hada Azul de Pinocho. Esta figura de fantasía renueva la esperanza de David, que se mantiene en una plegaria solo interrumpida por la congelación hasta ser rescatado por los especialistas, cuando la cosmolysis ya se ha consumado. David no valora como posible la opción de hacer una vida en común con los especialistas. Si su razón de existir era Monica, lo más lógico es que él renuncie a la vida cuando tiene la certeza de que ella no podrá volver nunca, por lo que elige «dormirse» junto al clon que los especialistas crean para sustituir a Monica durante un día que también transcurrirá en una recreación de la casa de los Swinton. Es la gran ilusión final íntegramente construida por sustitutos tanto de personajes como de escenarios.

\subsection{La polisemia del círculo, símbolo de un mundo sostenido por el sacrificio}

La escena de la separación en el bosque finaliza con un plano detalle del espejo retrovisor del coche de Monica, un espejo circular que ofrece el reflejo de David en plano medio picado (figura 34), quieto, cada vez más pequeño, más oscuro, según el coche se aleja de él (figura 35).

El plano detalle del espejo es un punto de crisis en el uso simbólico de los círculos en la película, que coincide con el momento en el que se revelarán las consecuencias anticosmogónicas de una cultura de la sustitución. El uso del círculo revela una simbología coherente que se desarrolla en tres momentos: antes del abandono, después del abandono y en el reencuentro final. Se ha indicado que el recurso del círculo en A.I. conecta con el empleo del mismo símbolo en 2001: A Space Odyssey (Kubrick, 1968), de forma que en ambos representaría la evolución y los ciclos vida-muerte (Alba, 2017, p. 169). Ahora mostraremos que las formas circulares también guardan relación con la figura del sustituto y del deseo insaciable.

Antes del abandono del mecha, en la casa de los Swinton, la relación de David y Monica está acompañada por los círculos (figuras 23 y 36-39). Suelen emplearse en momentos de cierta tranquilidad e incremento de cercanía afectiva entre personajes.

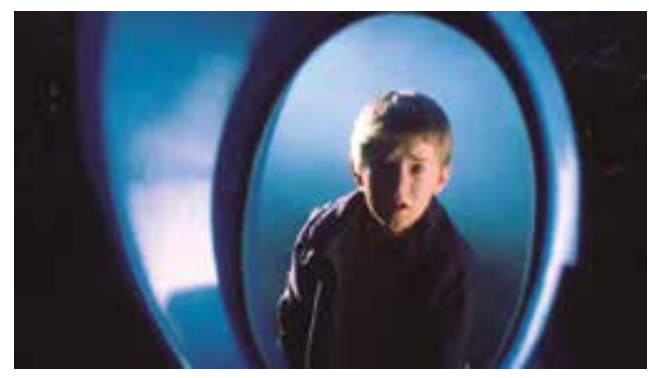

Figura 34. A.I. Artificial Intelligence, Steven Spielberg, 2001.

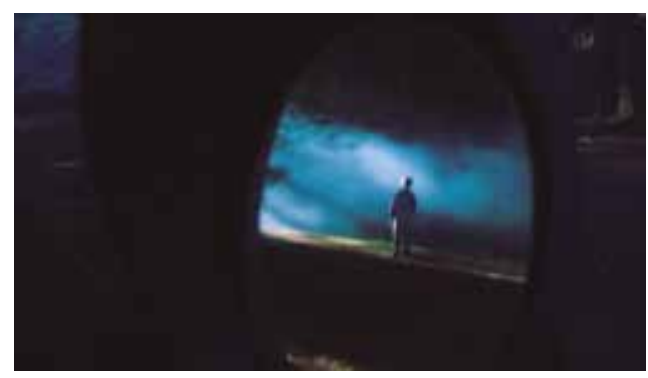

Figura 35. A.I. Artificial Intelligence, Steven Spielberg, 2001. 

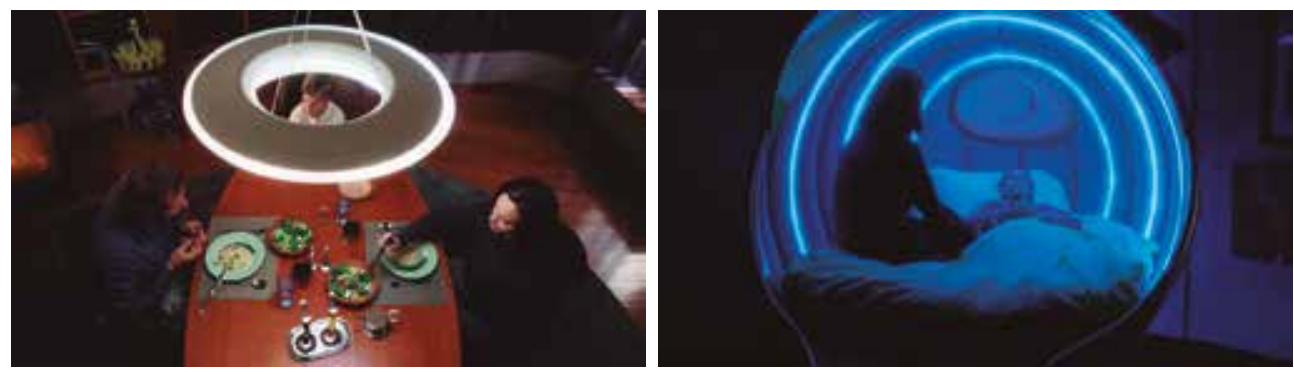

Figura 36. A.I. Artificial Intelligence, Steven Spielberg, Figura 37. A.I. Artificial Intelligence, Steven Spielberg, 2001. 2001.
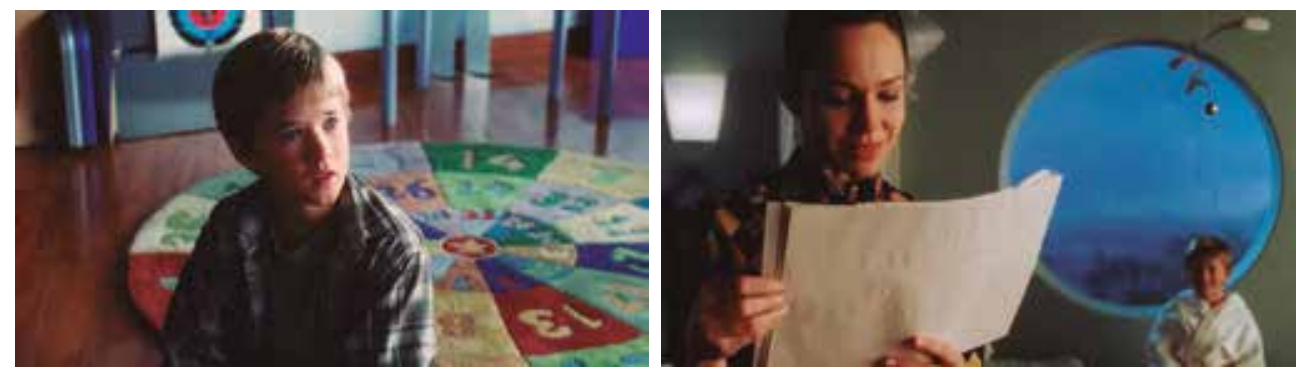

Figura 38. A.I. Artificial Intelligence, Steven Spielberg, Figura 39. A.I.Artificial Intelligence, Steven Spielberg, 2001. 2001.

Después del abandono del niño robot, durante las escenas ambientadas en Flesh Fair (figuras 26, 27, 40, 41 y 42), los círculos aparecen con insistencia portando sentidos muy diferentes: hostilidad, persecución, muerte. Ahora comunica ideas del todo contrarias a los círculos en el hogar de los Swinton. Uno y otro sentidos contribuyen al desarrollo del símbolo: el círculo acompaña al sustituto y víctima, que primero es acogido y protegido para luego ser arrojado a una existencia estructuralmente amenazada y orientada a su muerte ritual en un altar sacrificial también redondo (figura 42) ${ }^{[10]}$.

En el tramo final, los especialistas informan a David de que podrá pasar un día entero con un clon que reemplaza a su madre. La acción se desarrolla bajo el signo del círculo (figuras 43 y 44).

La ventana circular (figuras 43 y 44) es recuerdo del primer sentido del círculo, que remite a lo acogedor y hogareño (figura 39). Mientras que la luna (figura 43) recuerda el peligro y la intemperie (figuras 26,44 y 41). La nueva síntesis de esos dos significados está presente en
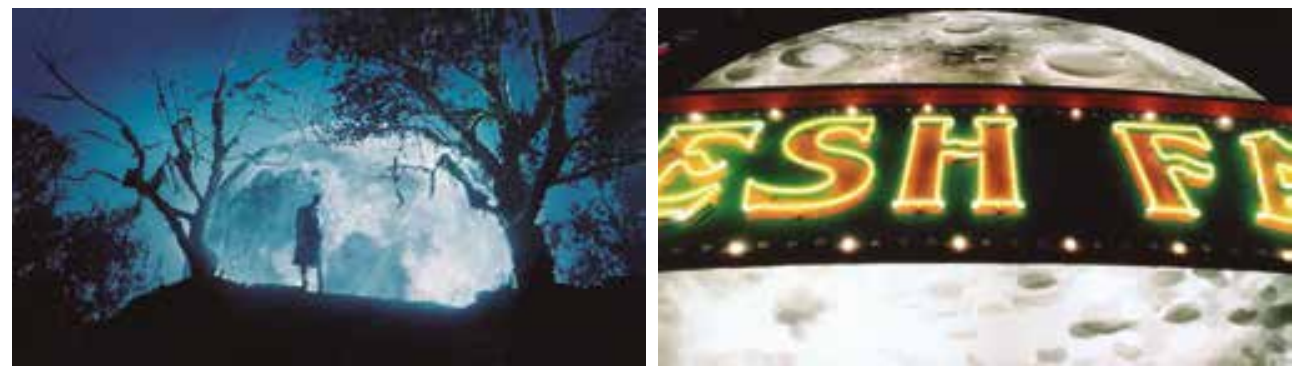

Figura 40. A.I. Artificial Intelligence, Steven Spielberg, Figura 41. A.I. Artificial Intelligence, Steven Spielberg, 2001. 2001. 


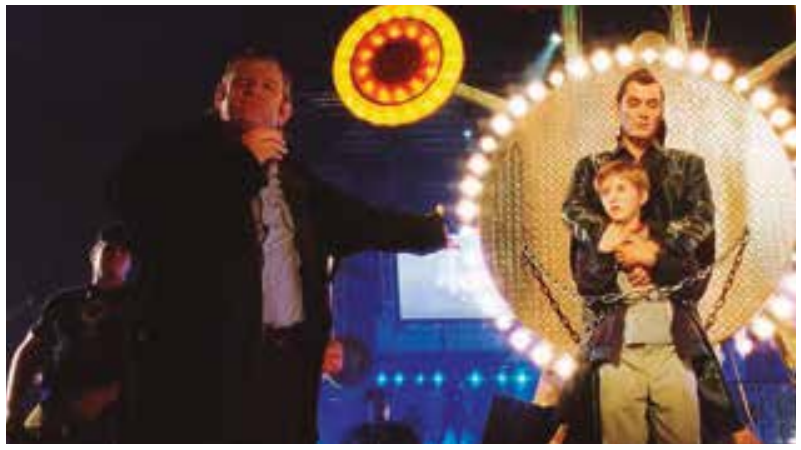

Figura 42. A.I. Artificial Intelligence, Steven Spielberg, 2001.

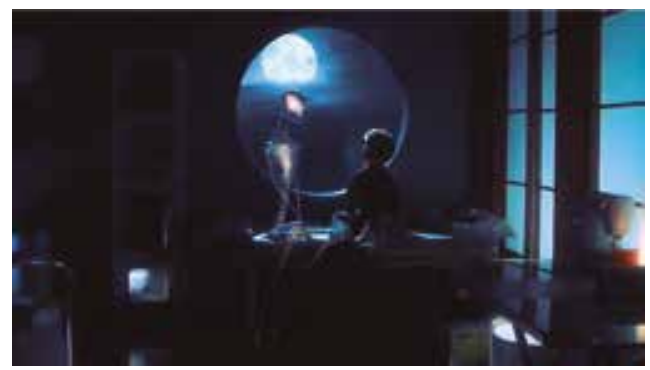

Figura 43. A.I.Artificial Intelligence, Steven Spielberg, Fig 2001.

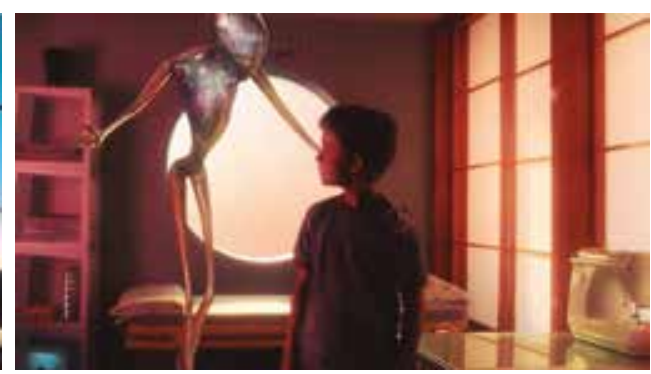

Figura 44. A.I. Artificial Intelligence, Steven Spielberg, 2001.

la ventana que ve alejarse la noche y deja traspasar la luz del astro rey (figura 44). La caducidad del clon de Monica revela definitivamente la verdad agridulce del mecanismo de sustitución. Ese día que ambos sustitutos pasan juntos resulta agridulce: el mundo posible que gira alrededor de la sustitución posee una obsolescencia programada. Este mundo terminal requiere constantemente de nuevos sustitutos, primero acogidos y luego sacrificados. En este sentido deben entenderse esos ciclos de vida y muerte simbolizados en la circunferencia.

\section{Conclusión}

Girard contemplaba solo como una posibilidad que la resolución sacrificial coincidiese con la desaparición de la misma humanidad, aunque él prefiere pensar que precisamente el sacrificio impide nuestra definitiva autodestrucción (Girard, 2010, pp. 15, 48). Ese primer supuesto posible es el que explora A.I. La película suscita y responde el interrogante sobre la viabilidad de un mundo donde la lógica dominante sea la de la sustitución. Spielberg parece defender que un mundo regido por la lógica de la sustitución avanza imparable hacia su propia destrucción, lo que hemos llamado anticosmogonía, cosmolysis, cosmoekmedenise, es decir, el ser humano exterminado definitivamente por sí mismo por medio de actos valorados moralmente como malos.

Según A.l., la cultura de la sustitución es la cultura de la muerte, porque mata al "Tú» reduciéndolo a mero objeto, liquida al «Yo» limitándolo a la figura de sujeto, elimina sacrificialmente al sustituto con la excusa de la pacificación de una sociedad que avanza hacia la parálisis absoluta, simbolizada en esa ciudad de Nueva York inundada en el comienzo y total- 
mente congelada en la parte final del filme. El motivo de esta decrepitud moral no es el mero desarrollo técnico, sino la inadecuada incorporación de la tecnología al proyecto de promoción de la vida humana auténtica. A.I. descubre el engaño de la sustitución, las tres etapas del desarrollo simbólico del círculo lo indican especialmente bien: el sustituto que al comienzo viene a satisfacer deseos egoístas y es recibido acogedoramente no tarda en cargar sobre sí todo el malestar de la familia, que no descansará hasta expulsarle a los límites de la existencia (Flesh Fair y Rouge City son sus dos mejores expresiones). Todo lo que rodea al sustituto es una gran ficción falsaria en la que objetos altamente sofisticados, los mechas, sustituyen a los seres humanos en lo que solo un humano puede ser y hacer.

Consideramos que nuestro recorrido demuestra suficientemente la hipótesis que planteamos al comienzo: la posición discursiva de A.l. defiende que un mundo estructurado por los mecanismos de sustitución agota las posibilidades auténticamente humanas y conduce a su propio exterminio.

\section{Biblografía}

Alba, F. (2017). El cine fantástico de Spielberg: Padres ausentes, niños perdidos. Madrid: Encuentro.

Brisset, D. E. (2011). Análisis fílmico y audiovisual. Barcelona: UOC.

Castillo, J. M. (2016). Televisión, realización y lenguaje audiovisual. Madrid: Instituto RTVE. Cavell, S. (1979). The World Viewed. Reflections on the Ontology of Film. Londres: Harvard University Press. [(1971). Nueva York, EE.UU.: The Viking Press].

Champeaux, G. de y Sterckx, D. S. (1985). Introducción a los símbolos, Madrid: Encuentro. [Original francés: (1972). Le monde des Symboles. St. Léger Vauban: Zodiaque].

Curtis, B., Kennedy, K., Spielberg, S. (productores) y Spielberg, S. (director) (2001). A.I. Artificial Intelligence [cinta cinematográfica]. E.U.: DreamWorks, Amblin Entertainment, Stanley Kubrick Productions.

Dunn, T. (2008). A.I.: Artificial Intelligence and the Tragic Sense of Life. En Kowalski, D. A. (ed.), Steven Spielberg and Philosophy (pp. 82-94). Kentucky, EE.UU.: The University Press of Kentucky.

Eco, U. (1994). The Limits of Interpretation. Bloomington, EE.UU.: Indiana University Press. Eliade, M. (2012). Lo sagrado y lo profano. Barcelona: Paidós. [Original alemán: (1957). Das Heilige und das Profane. Von Wesen des Religiösen. Reinbek bei Hamburgo: Rowohlt Taschenbuch Verlag].

Girard, R. (1989). La ruta antigua de los hombres perversos. Barcelona: Anagrama. [Original francés: (1985). Le route Antique des hommes pervers. París: Grasset \& Fasquelles].

Girard, R. (2010). Clausewitz en los extremos. Política, guerra y apocalipsis. Buenos Aires: Katz. [Original francés: (2007). Achever Clausewitz. París: Carnets Nord].

Girard, R. (2012). El sacrificio. Madrid: Encuentro. [Original francés: (2003). Le sacrifice. París: Bibliothèque Nationale de France].

García-Noblejas, J. J. (1988). Fundamentos para una iconología audiovisual. Comunicación y sociedad 1 (1), pp. 21-71. 
García-Noblejas, J. J. (2005). Comunicación y mundos posibles. Pamplona: EUNSA. González Vidal, J. y Morales Campos, A. (2019). Intertextualidad en Inteligencia Artificial, de Steven Spielberg. Tópicos del Seminario, 38, pp. 171-187. Recuperado de http://www. topicosdelseminario.buap. $\mathrm{mx} /$ index.php/topsem/article/view/510.

Guardini, R. (2014). Mundo y persona. Ensayos para una teoría cristiana del hombre. Madrid: Encuentro. [Original alemán: (1939). Welt und Person. Versuche zur christlichen Lehre vom Menschen. Bayer: Verlagsgemeinschaft Matthias-Grünewald].

Jess-Cooke, C. (2008). Virtualizing the Real: sequelization and secondary memory in Steven Spielberg's Artificial Intelligence: A. I. Screen 47 (3), pp. 347-365.

Kendrick, J. (2014). Darkness in the Bliss-Out. A reconsideration of the Films of Steven Spielberg. Nueva York, EE.UU.: Bloomsbury Academic.

Kubrick, S. (productor y director) (1968). 2001: A Space Odyssey [cinta cinematográfica]. Reino Unido, E.U.: Metro-Goldwyn-Mayer.

LaRocca, D. (ed.) (2020). The Thought of Stanley Cavell and Cinema. Turning anew to the Ontology of Film a Half-Century after The World Viewed. Nueva York, EE.UU.: Bloomsbury Academic.

Marín, H. (2019). Mundus. Una arqueología filosófica de la existencia. Granada: Nuevo Inicio. Morrissey, T. (2004). Growing Nowhere: Ponicchio Subverted in Spielberg's A.I. Artificial intelligence. Extrapolation 45 (3), pp. 249-262.

North, D. (2017). The Spielberg Effects. En N. Morris (ed.), A Companion to Steven Spielberg (pp. 389-409). Malden, EE.UU.: Wiley Blackwell.

Pavel, T. G. (1986). Fictional Worlds. Cambridge, EE.UU.: Harvard University Press.

Poythress, V. S. (2000). The Returning King: A Guide to the Book of Revelation. New Jersey, EE.UU.: Presbyterian and Reformed Publishing Company.

Williams, L. R. (2017). «Who am I, David?». Motherhood in Spielberg's Dramas of Family Dysfunction. En N. Morris (ed.), A Companion to Steven Spielberg (pp. 243-257). Malden, EE.UU.: Wiley Blackwell.

Zamorano Rojas, A. D. (2009). En busca del sujeto perdido: Inteligencia Artificial. Argumentos (Méx), 22 (60), pp. 139-162. Recuperado de http://www.scielo.org.mx/scielo. php?script=sci_arttext\&pid=S0187-57952009000200008.

Zubiri, X. (2010). Acerca del mundo. Madrid: Alianza.

\section{NotAS}

[1] El presente trabajo está vinculado al Grupo Estable de Investigación «Imaginación y mundos posibles", de la Facultad de Comunicación de la Universidad Francisco de Vitoria.

[2] David sustituye al hijo en coma de los Swinton; Gigolo Joe es el sustituto de un amante; Flesh Fair es un desguace de robots sustitutos; incluso la Monica que aparece al final de la película no es más que un clon de reemplazo para David.

[3] No profundizaremos en la ontología de la imagen fílmica. Que una película pueda entenderse en términos de mundo es una intuición que subyace a nuestra metodología. Para una primera aproximación a la idea de la imagen audiovisual como mundo, puede consultarse el clásico de Cavell The World Viewed (1979) o a sus más recientes comentaristas (LaRocca, 2020). 
[4] Aunque se ha indicado que «the film begins with the implication that human-created technological progress has sowed the seeds of what will eventually be its own self-destruction" (Kendrick, 2014, p. 183), nosotros defenderemos que esa semilla maligna es previa al avance tecnológico, es decir, que el uso de la técnica manifiesta algo ya corrompido previamente en el interior de la persona.

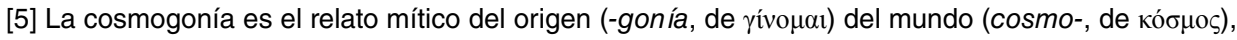
del mismo modo que la teogonía da cuenta del nacimiento (-gonía) de los dioses (teo-, de @zós). Nosotros empleamos el término anticosmogonía para expresar lo contrario: la muerte del mundo, su desaparición.

[6] El término "cosmolisis» ya se utiliza desde el siglo pasado en el ámbito de la ciencia, concretamente en Biología. Para separarnos de su sentido positivo proponemos el término cosmolysis, que se refiere a la disolución (-lysis, de $\lambda v ́ \sigma \varsigma$ ) del mundo (cosmo-) como un proceso que finaliza en la desaparición total e irreversible del sistema de posibilidades.

[7] Con el mismo sentido que anticosmogonía y cosmolysis, utilizamos cosmoekmedenise, la aniqui-

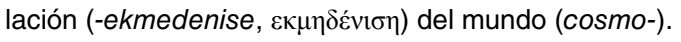

[8] Habitualmente se emplea el adjetivo «apocalíptico» para referirse a relatos en los que suceden catástrofes globales. También es habitual definir un relato que narra las peripecias de unos personajes tras un desastre nuclear planetario como «postapocalíptico». Nosotros preferimos evitar tales expresiones, ya que hacen un uso reductivo de la idea de lo «apocalíptico» y desdibujan su sentido fundamental. El verbo $\alpha \pi$ ок $\alpha \lambda \dot{ } \pi \tau \omega$, transliterado como «apocalypto", significa revelar, de modo que un

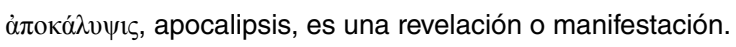

[9] Hobby crea y comercializa una línea de niños robots «capaces de amar»; Monica deja al niño robot David en el bosque; Martin, el hijo de Monica, provoca constantemente a David para crear situaciones peligrosas; un marido despechado mata a su propia mujer y urde una intriga que señala al robot Gigolo Joe como culpable; los espectadores de Flesh Fair participan en una actividad asombrosamente violenta; etcétera.

[10] En la teoría mimética el círculo remite principalmente a la masa indiferenciada que rodea a la víctima. 